\title{
Efficient numerical analysis of transient heat transfer by Consecutive-Interpolation and Proper Orthogonal Decomposition
}

\author{
Nguyen Ngoc Minh, Nguyen Thanh Nha, Truong Tich Thien*, Bui Quoc Tinh
}

\begin{abstract}
The consecutive-interpolation technique has been introduced as a tool enhanced into traditional finite element procedure to provide higher accurate solution. Furthermore, the gradient fields obtained by the proposed approach, namely consecutive-interpolation finite element method (CFEM), are smooth, instead of being discontinuous across nodes as in FEM. In this paper, the technique is applied to analyze transient heat transfer problems. In order increase time efficiency, a modelreduction technique, namely the proper orthogonal decomposition (POD), is employed. The idea is that a given large-size problem is projected into a small-size one which can be solved faster but still maintain the required accuracy. The optimal POD basis for projection is determined by mathematical operations. With the combination of the two novel techniques, i.e. consecutive-interpolation and proper orthogonal decomposition, the advantages of numerical solution obtained by CFEM are expected to be maintained, while computational time can be significantly saved.
\end{abstract}

Index Term-three-dimensional transient heat transfer, CFEM, POD, consecutive interpolation.

Received: 07-3 -2017, Accepted: 20-11-2017.

This research is funded by Ho Chi Minh city University of Technology - VNU-HCM, under grant number T-KHUD2016-108. We are also grateful to our colleagues from Department of Engineering Mechanics for valuable discussions which help to conduct the study.

Nguyen Ngoc Minh, Nguyen Thanh Nha, Truong Tich Thien - Department of Engineering Mechanics, Faculty of Applied Sciences, Ho Chi Minh City University of Technology,VNU-HCM. Email: tttruong@hcmut.edu.vn

Bui Quoc Tinh - Dept. of Mechanical and Environmental Informatics, Tokyo Institute of Technology, 2-12-1-W8-22, Ookayama, Meguro-ku, Tokyo, 152-8552, Japan

\section{INTRODUCTION}

$\mathrm{O}$ NE may encounter heat transfer problems in many human activities. For example, all three types of heat transfer can be found in cooking, i.e conduction, convection and radiation. Design of air-conditioning system is usually based on knowledge of heat convection. Day by day, the Earth is receiving heat from the Sun by thermal radiation. In industry, heat transfer analysis is required in many fields of engineering, such as mechanical engineering, electrical engineering, aeronautical engineering, etc. However, analytical solutions are only available for some specific problems, most of which are described with relatively simple geometry and boundary conditions. When it comes to deal with complicated geometries and/or boundary conditions, which are usually the cases of engineering applications, numerical analysis seems to be a more practical approach. Currently, the standard finite element (FEM) [1] has been widely used for heat transfer problems due to its simplicity and reasonable accuracy. However, several shortcomings of the method have been pointed out, see [2]. The FEM shape function is $\mathrm{C} 0$ continuous, resulting in non-physical discontinuity of gradient fields, e.g. temperature gradient in case of heat transfer problems.

As alternatives to FEM, various other methods have been proposed for heat transfer analysis, such as the Boundary Element Method (BEM) [3] and the class of meshfree method $[4,5]$. On the other hand, amendments that can be integrated into FEM was also suggested to overcome the weakness while keeping the familiar FEM framework. In recent years, the consecutive-interpolation procedure (CIP) has been introduced as an enhancement for traditional FEM, to develop the 
so-called Consecutive-interpolation Finite Element Method (CFEM). In CFEM, the continuity of gradient fields is improved by taking the averaged nodal gradients into interpolation. Interestingly, the number of degrees of freedom are equal to that of FEM, given the same mesh. The CFEM was first investigated for two-dimensional linear elastic problems $[6,7]$ and later was further developed for heat transfer analyis in two-dimensional space [8] and three-dimensional space [9]. A general formulation which allows application of CFEM in a wide range of finite elements was also proposed in [9].

As a model reduction method, the Proper Orthogonal Decomposition (POD) was introduced to reduce the computational time by projecting the problem of interest to another one which is much smaller in size. Hence, computer memory and elapsed time can be greatly saved. POD has been applied to structural vibration analysis based on experiments [10]. Investigation on combination of POD with finite element analysis of heat transfer problems is discussed by [11].

In this study, POD is combined with CFEM to effectively save computational time in the context of three-dimensional transient thermal analysis, such that the applicability of CFEM is further expanded. The proposed procedure is named by CFEM-POD for brevity while the CFEM without POD is mentioned by CFEM.

The paper is organized as follows. After the introduction, a brief review on application of CIP to three-dimensional element is presented in Section 2. The integration of POD into analysis is discussed in Section 3. In Section 4, the efficiency and accuracy of the proposed formulation are investigated by several numerical examples. Concluding remarks are given in Section 5.

\section{CONSECUTIVE-INTERPOLATION FOR HEAT TRANSFER PROBLEMS}

\subsection{Brief on consecutive-interpolation}

Let us consider a $3 \mathrm{D}$ body in the domain $\Omega$ bounded by $\Gamma=\Gamma_{\mathrm{u}}+\Gamma_{\mathrm{t}}$ và $\Gamma_{\mathrm{u}} \cap \Gamma_{\mathrm{t}}=\{\varnothing\}$. In finite element analysis, the domain $\Omega$ is discretized into non-overlapping sub-domains $\Omega_{\mathrm{e}}$ called elements. The points interconnected by the elements called nodes. Each node is associated with a shape function. Any function $u(\mathbf{x})$ defined in $\Omega$ can be approximated by a linear combination as

$$
u(\mathbf{x}) \approx \tilde{u}(\mathbf{x})=\sum_{i=1}^{n} N_{i}(\mathbf{x}) \hat{u}_{i}=\mathbf{N} \hat{\mathbf{u}}
$$

Here $n$ is the number of nodes, $\hat{\mathbf{u}}$ is the vector containting nodal values and $\mathbf{N}$ is the vector of shape functions. By assigning the approximated value at node $i$ as $u^{[i]}=u\left(\mathbf{x}_{i}\right)$, and the vector of shape functions evaluated at node $i$ as $\mathbf{N}^{[i]}=\mathbf{N}\left(\mathbf{x}_{i}\right)$, the average nodal derivatives $\bar{u}_{, x}^{[i]}$ (similarly for $\bar{u}_{, y}^{[i]}$ and $\bar{u}_{, z}^{[i]}$ ) can then be determined by $[6,7,9]$

$$
\bar{u}_{, x}^{[i]}=\overline{\mathbf{N}}_{, x}^{[i]} \hat{\mathbf{u}}
$$

in which the vector of averaged derivative $\overline{\mathbf{N}}_{, x}^{[i]}$ is calculated by

$$
\overline{\mathbf{N}}_{, x}^{[i]}=\sum_{e \in S_{i}}\left(w_{e} \cdot \mathbf{N}_{, x}^{[i][e]}\right)
$$

In Eq. (3), $\mathbf{N}_{, x}^{[i][e]}$ denotes the derivative of $\mathbf{N}^{[i]}$ computed in element $e$. $S_{i}$ is the set containing all the elements connected to node $i$, and $w_{\mathrm{e}}$ is a weight function defined by [9]

$$
w_{e}=\frac{\Delta_{e}}{\sum_{\bar{e} \in S_{i}} \Delta_{\bar{e}}},
$$

with $\Delta_{e}$ being the volume of element $e \in S_{i}$.

One well-known shortcoming of the standard FEM is the non-physical discontinuity of gradient fields, e.g. temperature gradient in case of heat transfer analysis. Such drawback can be overcome by taking both the averaged nodal derivatives $\bar{u}_{, x}^{[i]}$ (and $\bar{u}_{, y}^{[i]}$ and $\bar{u}_{, z}^{[i]}$ ) and the nodal values $u^{[\mathrm{i}]}$ and into interpolations, following the consecutiveinterpolation procedure (CIP) [9]. By means of CIP scheme, the approximation in Eq. (1) can be rewritten as

$$
\begin{aligned}
\widetilde{u}(\mathbf{x}) & =\sum_{i=1}^{n}\left(\phi_{i} u^{[i]}+\phi_{i x} \bar{u}_{, x}^{[i]}+\phi_{i y} \bar{u}_{, y}^{[i]}+\phi_{i z} \bar{u}_{, z}^{[i]}\right) \\
& =\mathbf{R}(\mathbf{x}) \hat{\mathbf{u}}
\end{aligned}
$$

In Eq. (5), the CIP shape functions is given by

$\mathbf{R}(\mathbf{x})=\sum_{i=1}^{n}\left(\phi_{i} \mathbf{N}^{[i]}+\phi_{i x} \overline{\mathbf{N}}_{, x}^{[i]}+\phi_{i y} \overline{\mathbf{N}}_{, y}^{[i]}+\phi_{i z} \overline{\mathbf{N}}_{, i z}^{[i]}\right), \quad$ in

which $\phi_{i}, \phi_{i x}, \phi_{i y}$ and $\phi_{i z}$ are the auxiliary 
functions dependent on the element type. Determination of auxiliary functions used to be bottleneck in application of CIP into finite element analysis, i.e. CFEM. However, a general formulation recently suggested by [9] can be used to determine auxiliary functions for a wide range of standard finite element types. For the sake of completeness, the formulation will be briefly presented here. Let us denote the following terms

$$
A_{1}=\sum_{i=1}^{n} L_{i} \text { and } A_{2}=\sum_{i=1}^{n} L_{i}^{2}
$$

where $n$ is the number of nodes within the element of interest and $L_{\mathrm{i}}$ is the Lagrange shape function associated with the $i^{\text {th }}$ node of the element. The functions $\phi_{i}$ and $\phi_{i x}$ can be written by

$$
\begin{gathered}
\phi_{i}=L_{i}+L_{i}^{2}\left(A_{1}-L_{i}\right)-L_{i}\left(A_{2}-L_{i}^{2}\right) \\
\phi_{i x}=\sum_{j=1, j \neq i}^{n}\left(x_{j}-x_{i}\right)\left(L_{i}^{2} L_{j}+\frac{1}{2} L_{i} L_{j}\left(A_{1}-L_{i}-L_{j}\right)\right)
\end{gathered}
$$

In Eq. (8), $x_{i}$ and $x_{j}$ denote the $x$-coordinate of node $i$ and node $j$, respectively. Functions $\phi_{i y}$ and $\phi_{i z}$ are obtained analogously by replacing $x$ coordinate in Eq. (8) with $y$-coordinate and $z$ coordinate, respectively.

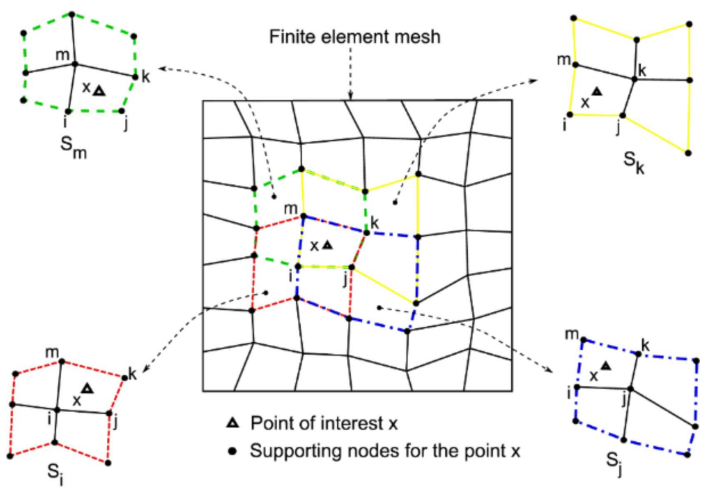

Figure 1. Schematic sketch of CQ4 element

Figure 1 illustrates the application of CIP approach into the four-node quadrilateral (Q4) element, which results in the namely CQ4 element. Without loss of generality, the scheme is described particularly in an irregular finite element mesh. As shown in Figure 1, the supporting nodes for the point of interest $\mathbf{x}$ include all the nodes in the four sets $S_{i}, S_{j}, S_{k}, S_{m}$, which contain all the adjacent elements that share the nodes $i, j, k, m$, respectively. Thus, the support domain for a point $\mathbf{x}$ in CQ4 element is larger than that in the standard Q4, since it includes not only the nodes of the element in interest but also the nodes of the neighboring elements. Similar observation is reported by [9] for the case of tetrahedral element, as shown in Figure 2.

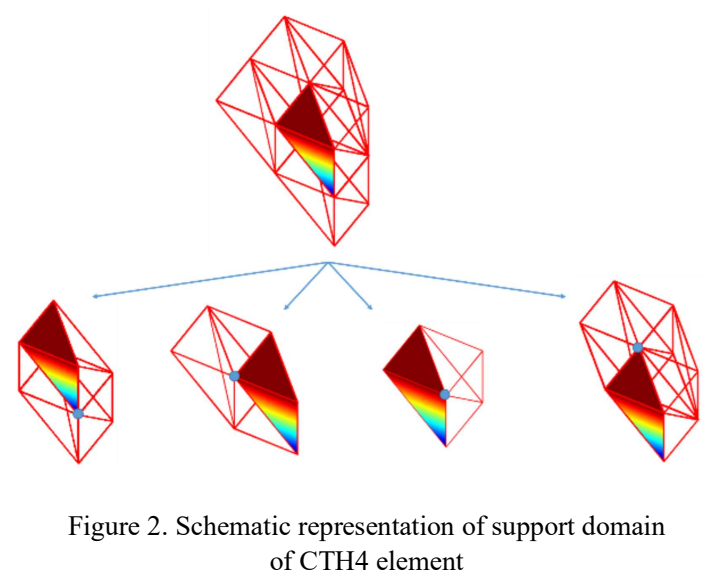

\subsection{Governing equations of heat transfer problems}

The governing equation of a heat transfer problem in a domain $\Omega$ is given by

$$
\nabla \cdot(\mathbf{k} \nabla T)+Q=\rho c \dot{T}
$$

with the following boundary conditions

$$
\begin{aligned}
& T=\bar{T} \text { on } \Gamma_{1}: \text { Dirichlet boundary } \\
& -k \nabla T=\bar{q} \text { on } \Gamma_{2}: \text { surface heat flux } \\
& -k \nabla T=0 \text { on } \Gamma_{3}: \text { adiabatic boundary } \\
& -k \nabla T=h\left(T_{a}-T\right) \text { on } \Gamma_{4} \text { : convection }
\end{aligned}
$$

In Eqs. (9) to (13), $\mathbf{k}=\operatorname{diag}\left(k_{\mathrm{xx}}, k_{\mathrm{yy}}, k_{\mathrm{zz}}\right)$ is the tensor of thermal conductivities; $T$ is the temperature field; $\mathrm{Q}$ is the body heat flux; $\rho$ is the density; $c$ is the specific heat capacity; $h$ is the convective coefficient; and $T_{\mathrm{a}}$ is the ambient temperature. Multiplying both sides of Eq. (9) with an arbitrary test function $\delta T$, then applying Green's theorem and integration by parts, the variational form is obtained as follows 


$$
\begin{aligned}
& \int_{\Omega} \delta T \cdot \dot{T} \mathrm{~d} \Omega+\int_{\Omega} \delta \nabla T k \nabla \mathrm{T} \mathrm{d} \Omega+\int_{\Gamma_{3}} \delta T h T \mathrm{~d} \Gamma \\
& -\int_{\Omega} \delta T \cdot Q \mathrm{~d} \Omega-\int_{\Gamma_{t}} \delta u \cdot \bar{q} \mathrm{~d} \Gamma-\int_{\Gamma_{3}} \delta T h T_{a} \mathrm{~d} \Gamma=0
\end{aligned}
$$

Using the approximation in Eq. (5) for both temperature $T$ and test function $\delta T$, one gets

$$
\begin{aligned}
T & =\mathbf{R T}, \delta T=\mathbf{R} \delta \mathbf{T} \\
\nabla T & =\mathbf{B T}, \delta \nabla T=\mathbf{B} \delta \mathbf{T}
\end{aligned}
$$

where matrix $\mathbf{B}$ calculates the derivatives of shape functions $\mathbf{R}$. The discrete form is obtained by substitution of Eqs. (16-17) into Eq. (15)

$$
\mathbf{M T}+\mathbf{K T}=\mathbf{F}
$$

in which $\mathbf{M}$ is the matrix related to the specific heat capacitance, $\mathbf{K}$ is the matrix related to conductivity and convection terms, while $\mathbf{F}$ is the vector accounts for heat source and thermal interaction with external environment.

$$
\begin{aligned}
& \mathbf{M}=\int_{\Omega} \mathbf{R}^{T} \rho c \cdot \mathbf{R} \mathrm{d} \Omega \\
& \mathbf{K}=\int_{\Omega} \mathbf{B}^{T} k \mathbf{B} \mathrm{d} \Omega+\int_{\Gamma_{3}} \mathbf{R}^{T} h \mathbf{R} \mathrm{d} \Gamma \\
& \mathbf{F}=\int_{\Omega} \mathbf{R}^{T} Q \mathrm{~d} \Omega+\int_{\Gamma_{1}} \mathbf{R}^{T} \bar{q} \mathrm{~d} \Gamma+\int_{\Gamma_{3}} \mathbf{R}^{T} h T_{a} \mathrm{~d} \Gamma
\end{aligned}
$$

\section{PROPER ORTHOGONAL DECOMPOSITION (POD).}

The Proper Orthogonal Decomposition (POD) was initially developed to statistically analyze experimental data. Firstly, a series of snapshots are generated. Each snapshot is actually a vector containing data of system response at a specified time period. An orthogonal basis is then obtained from the snapshots. The orthogonal basis is constructed such that it reduces the size of the problem to be solved, but the required accuracy is still kept. Due to the reduction of problem size, computational cost can be greatly saved. Finally, the full system can then be reproduced from the reduced system without much loss of accuracy.

Denoting the column vector $\mathbf{T}_{\mathrm{i}}, i=1,2, \ldots, d$, as the response at the $i^{\text {th }}$ time step and $d$ is the total number of time steps, the set of snapshots can be expressed by an $n \times d$ matrix, with $n$ being the total number of degrees of freedom

$$
\mathbf{T}_{\text {snap }}=\left[\begin{array}{llll}
\mathbf{T}_{1} & \mathbf{T}_{2} & \cdots & \mathbf{T}_{d}
\end{array}\right]
$$

By using singular value decompositions, the matrix $\mathbf{T}_{\text {snap }}$ can be decomposed into three parts as follows

$$
\mathbf{T}_{\text {snap }}=\mathbf{U D V}
$$

where $\mathbf{V}$ is an orthogonal matrix of size $d \mathbf{x} d$; $\mathbf{D}$ is the rectangular matrix of size $n \times d$ containing the singular values; while the $n \times{ }^{2} n$ matrix $\left[\begin{array}{llll}\varphi_{1} & \varphi_{2} & \cdots & \varphi_{n}\end{array}\right]$ stores the orthogonal eigenvectors of $\mathbf{T}_{\text {snap }} \mathbf{T}_{\text {snap }}^{T}$. In matrix $\mathbf{D}$, only values along the diagonal are non-negative and named by singular values, while the rest are all zero. In practice, matrix $\mathbf{D}$ is sorted such that the singular values are arranged in decreasing order, i.e. $\lambda_{1} \geq \lambda_{2} \geq \cdots \geq \lambda_{r} \geq 0$, with $r=\min (n, d)$. Denoting $\Phi=\mathbf{U D}$, the snapshot matrix is rewritten by

$$
\mathbf{T}_{\text {snap }}=\Phi \mathbf{V}
$$

Since $\boldsymbol{\Phi}$ is orthogonal, $\mathbf{V}$ can be calculated by

$$
\mathbf{V}=\Phi^{T} \mathbf{T}_{\text {snap }}
$$

The snapshot matrix can be approximated by a truncated basis $\bar{\Phi}$ where $\bar{\Phi}$ is the first $k$ columns of $\Phi$

$$
\mathbf{T}_{\text {snap }} \approx \bar{\Phi} \overline{\mathbf{V}} \Rightarrow \overline{\mathbf{V}}=\bar{\Phi}^{T} \mathbf{T}_{\text {snap }}
$$

The truncation error of approximation is determined by

$$
\varepsilon=\mathbf{T}_{\text {snap }}-\bar{\Phi} \overline{\mathbf{V}}=\mathbf{T}_{\text {snap }}-\bar{\Phi} \bar{\Phi}^{T} \mathbf{T}_{\text {snap }}
$$

Due to orthogonality, $\mathbf{I}=\bar{\Phi} \bar{\Phi}^{T}$ is an identity matrix. The key point in POD procedure is to determine $k$ such that truncation error less than a given tolerance. Similar to [12], the cumulative "energy" coefficient is defined by

$$
e(k)=\frac{\sum_{i=1}^{k} \lambda_{i}}{\sum_{j=1}^{r} \lambda_{j}}, k \leq r
$$

Here, $e(k)$ represents the ratio of "energy" in the total first $k$ modes with respect to the total "energy". As $k$ increases, the truncation error reduces. Once the POD basis is selected, the following reduced problem can be obtained

$$
\overline{\mathbf{M T}}+\overline{\mathbf{K}} \overline{\mathbf{T}}=\overline{\mathbf{F}},
$$

which can be solved much faster than Eq. (17) due to the smaller size. The terms in Eq. (28) are determined by 


$$
\begin{aligned}
& \overline{\mathbf{M}}=\boldsymbol{\Phi}^{T} \mathbf{M \Phi}, \overline{\mathbf{K}}=\boldsymbol{\Phi}^{T} \mathbf{K} \boldsymbol{\Phi}, \\
& \overline{\mathbf{F}}=\boldsymbol{\Phi}^{T} \mathbf{F}, \overline{\mathbf{T}}=\boldsymbol{\Phi}^{T} \mathbf{T},
\end{aligned}
$$

\section{NUMERICAL EXAMPLES.}

In this section, three numerical examples are investigated to demonstrate the effectiveness of the proposed procedure. We denote Q4 for the standard four-node quadrilateral element and TH4 for the tetrahedral element, while CQ4 and CTH4 are the CIP-version of Q4 and TH4, respectively.

\subsection{Two-dimensional heat transfer}

Let us consider a square domain (see Figure 3) of size $\mathrm{L} \times \mathrm{L}$, where $\mathrm{L}=\pi \mathrm{m}$. On all four boundaries of the square, zero temperature, $\mathrm{T}=0$ ${ }^{\circ} \mathrm{C}$, is imposed. Initially, the temperature distribution is given by the following equation:

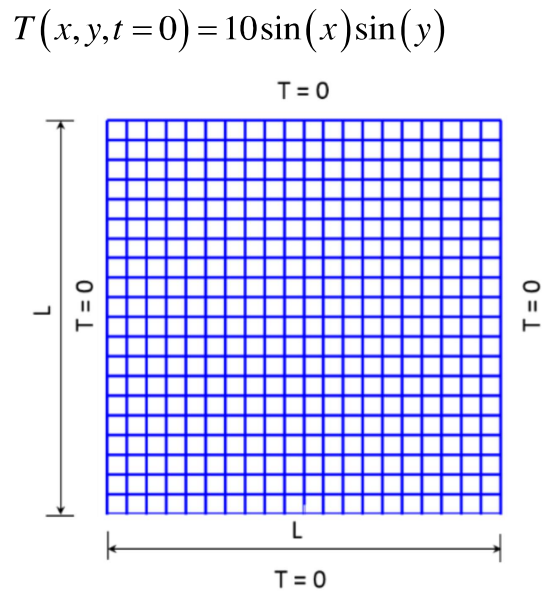

Figure 3. Example 4.1: Geometry

Material properties are given as follows: the mass density $\rho=1 \mathrm{~kg} / \mathrm{m}^{3}$, the specific heat $c=1$ $\mathrm{J} /\left(\mathrm{kg}{ }^{\circ} \mathrm{C}\right)$, and the heat conductivity $k=1 \mathrm{~W} /(\mathrm{m}$ $\left.{ }^{\circ} \mathrm{C}\right)$. Under the boundary conditions specified above, the temperature tends to drop down from the initial value to zero as given by follows [13]

$$
T(x, y, t)=10 \sin (x) \sin (y) e^{-2 t}
$$

Two levels of finite element mesh are used in numerical simulation: 20x20 CQ4 elements and 40x40 CQ4 elements (i.e. 441 and 1681 degrees of freedom). Firstly, the matrix of snapshots $\mathbf{T}_{\text {snap }}$ is generated for a time span of $\mathrm{t}=0.5 \mathrm{~s}$ with time increment $\Delta \mathrm{t}=0.02 \mathrm{~s}$, i.e. 25 time steps. Next, singular decomposition is calculated for $\mathbf{T}_{\text {snap }}$. As shown in Table 1, the first singular value (the largest one) dominates. Thus, it is reasonable to select a POD basis of size $k=3$ to approximate the response of the system. The reduced system is obtained using Eq. (30). Finally, solution for time span of $t=3$ s, i.e. 150 time steps, is computed by the reduced system.

Table 1. Example 4.1: Magnitude of the three largest singular values of matrix $\mathrm{T}_{\text {snap }}$

\begin{tabular}{|l|l|l|l|}
\hline Mesh & $1^{\text {st }}$ value & $2^{\text {nd }}$ value & $3^{\text {rd }}$ value \\
\hline $20 \times 20$ CQ4 & $\sim 10^{2}$ & $\sim 10^{-13}$ & $\sim 10^{-13}$ \\
\hline $40 \times 40 \mathrm{CQ} 4$ & $\sim 10^{2}$ & $\sim 10^{-13}$ & $\sim 10^{-13}$ \\
\hline
\end{tabular}

The results evaluated by CQ4-POD are compared with both CQ4 and analytical solutions (see Eq. (32)). The temperature along the line $\mathrm{y}=\pi / 2$ evaluated at $\mathrm{t}=1 \mathrm{~s}, \mathrm{t}=2 \mathrm{~s}$ and $\mathrm{t}=3 \mathrm{~s}$ are depicted in Figure 4. At $\mathrm{t}=3 \mathrm{~s}$, temperature is almost zero at every node, indicating a steady state is reached. Note that snapshot matrix is only calculated from $\mathrm{t}=0$ to $\mathrm{t}=0.5 \mathrm{~s}$. Hence, the reduced system obtained by POD is able to predict responses taking place after snapshots have been generated.

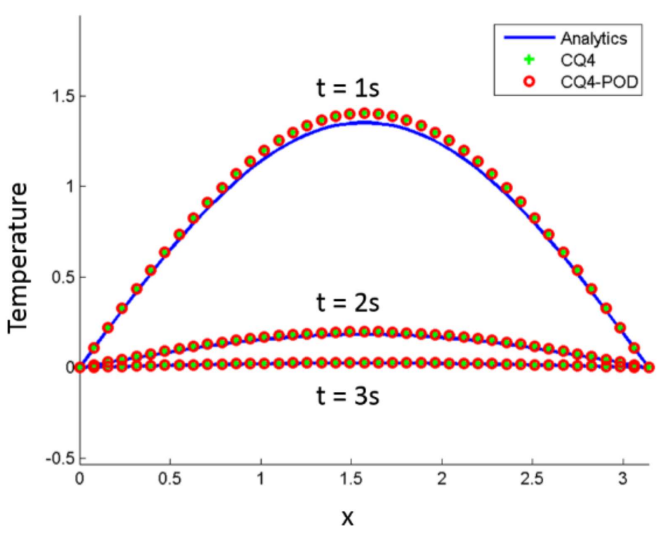

Figure 4. Example 4.1: Temperature along the line $\boldsymbol{y}=\frac{\pi}{2}$ evaluated at $\mathrm{t}=1 \mathrm{~s}, \mathrm{t}=2 \mathrm{~s}$ and $\mathrm{t}=3 \mathrm{~s}$

Relative errors between values computed by CQ4 only and by CQ4-POD at $\mathrm{t}=1 \mathrm{~s}$ with respect to analytical solutions are reported in Table 2 . Results show that the accuracy of CQ4-POD is almost equivalent to CQ4, despite the fact that the reduced system has only 3 degrees of freedom, much smaller than the full system. Computational time in CQ4-POD (including the time required for 
generating snapshots) is greatly reduced, especially when finer mesh is used, see Table 3.

Table 2. Example 4.1: Relative errors between CQ4 and CQ4POD with analytical solutions, at $t=1 \mathrm{~s}$

\begin{tabular}{|l|l|l|}
\hline Mesh & CQ4 & CQ4-POD \\
\hline $20 \times 20$ CQ4 & $3.97 \%$ & $4.28 \%$ \\
\hline $40 \times 40$ CQ4 & $3.95 \%$ & $3.97 \%$ \\
\hline
\end{tabular}

Table 3. Example 4.1: Computational time

\begin{tabular}{|l|l|l|}
\hline Mesh & CQ4 & CQ4-POD \\
\hline $20 \times 20 \mathrm{CQ} 4$ & $\sim 24 \mathrm{~s}$ & $\sim 24 \mathrm{~s}$ \\
\hline $40 \times 40 \mathrm{CQ} 4$ & $\sim 90 \mathrm{~s}$ & $\sim 55 \mathrm{~s}$ \\
\hline
\end{tabular}

\subsection{Three-dimensional heat transfer}

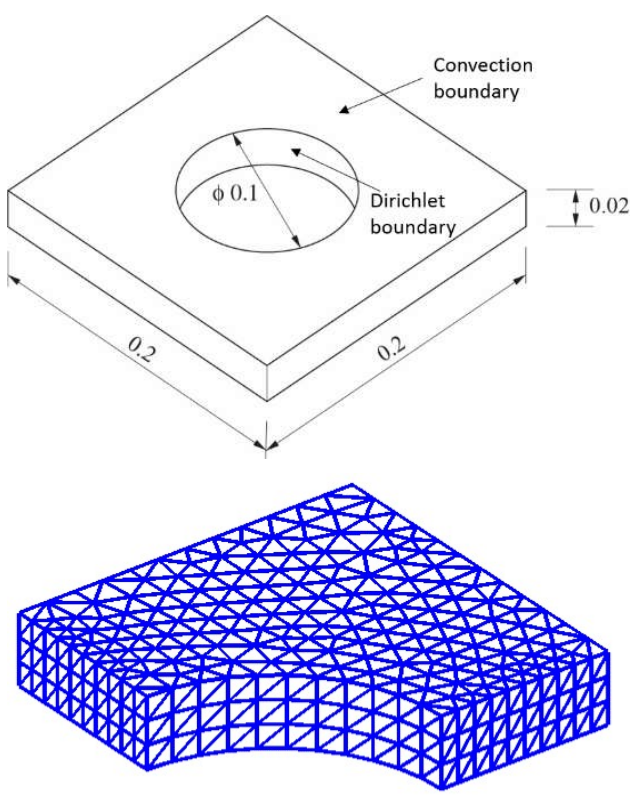

Figure 5. Example 4.2: Geometry (upper) and one-quarter model (lower)

In this example, three-dimensional transient heat transfer in a square plate with a cylindrical hole at center is investigated. The plate is subjected to both convection and Dirichlet boundary conditions, as shown in Figure 5. Due to symmetry, only one-quarter of the plate is modeled.

Material properties are given as follows: homogeneous conductivity $k=15 \mathrm{~W} / \mathrm{m}^{\circ} \mathrm{C}$, density $\rho=7800 \mathrm{~kg} / \mathrm{m}^{3}$ and specific heat capacitance $c=$
$125 \mathrm{~J} / \mathrm{kg}{ }^{\circ} \mathrm{C}$. Initially, the entire plate is kept at 50 ${ }^{\circ} \mathrm{C}$. In the hole, the temperature is prescribed at $T_{\mathrm{w}}$ $=200{ }^{\circ} \mathrm{C}$. Convection takes place on the top surface with a coefficient of $h=200 \mathrm{~W} / \mathrm{m}^{2}{ }^{\circ} \mathrm{C}$, and the ambient temperature is set by $\mathrm{T}_{\mathrm{a}}=100{ }^{\circ} \mathrm{C}$.

Table 4. Example 4.2: Relative errors between CTH4 and CTH4-POD values at various periods

\begin{tabular}{|c|c|c|c|}
\hline Time & $\mathrm{t}=75 \mathrm{~s}$ & $\mathrm{t}=250 \mathrm{~s}$ & $\mathrm{t}=750 \mathrm{~s}$ \\
\hline Relative Errors & $0.13 \%$ & $0.087 \%$ & $0.082 \%$ \\
\hline
\end{tabular}

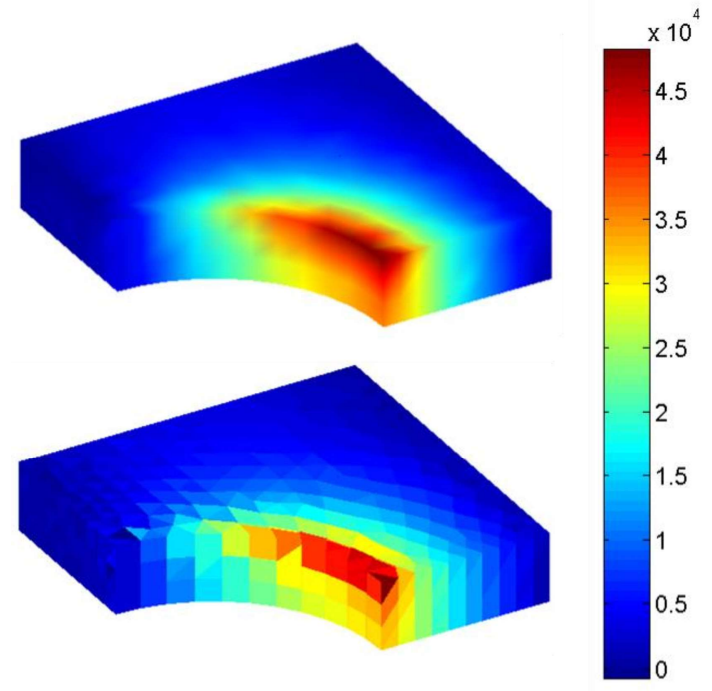

Figure 6. Example 4.2: The $\mathrm{x}$-component of heat flux at $\mathrm{t}=$ 750s, obtained by CTH4-POD (upper) and TH4 (lower)

For numerical simulation, a mesh of 3428 consecutive-interpolation four-node tetrahedral elements (CTH4), i.e. 848 nodes, is used to discretize the domain. The snapshot matrix $\mathbf{T}_{\text {snap }}$ is generated by CTH4 solutions for a time span of $75 \mathrm{~s}$ with 75 time steps, i.e. time increment $\Delta \mathrm{t}=1 \mathrm{~s}$. Based on singular value decomposition of $\mathbf{T}_{\text {snap, }}$ a set of 24 POD bases is chosen (largest singular value is of magnitude $10^{3}$ and the $24^{\text {th }}$ singular value is of magnitude $10^{-9}$ ). POD procedure is then used to predict temperature changing from $t=0$ to $t=750 \mathrm{~s}$. Table 4 presents the relative errors between CTH4-POD and CTH4 solutions at $\mathrm{t}=$ $125 \mathrm{~s}, \mathrm{t}=500 \mathrm{~s}$ and $\mathrm{t}=750 \mathrm{~s}$. The errors are all smaller than 1\%. Elapsed time of CTH4-POD is approximately 160s, quite smaller than that of CTH4, which is approximately 176s. Figure 6 depicts the x-component of heat flux, showing that heat flux computed by CTH4 elements is smooth, while the one obtained by TH4 elements (standard 
FEM) is non-physically discontinous. Hence, CTH4-POD preserves the desirable property of CTH4, such that the nodal gradients are continous.

\subsection{Heat transfer in a 3D complicated domain}

Heat transfer through a 3D domain with complicated geometry is considered in this example, see Figure 6. The conductivity for this example is set to be $k=100 \mathrm{~W} / \mathrm{m}^{\circ} \mathrm{C}$. The inward heat flux is applied by $q=20000 \mathrm{~W} / \mathrm{m}^{2}$ on the curved surface of the middle fin. Convection takes place on the left hand side surface $(x=0)$ with an ambient temperature of $T_{\mathrm{a}}=300{ }^{\circ} \mathrm{C}$ and convection coefficient $h=100 \mathrm{~W} / \mathrm{m}^{2}$. On the right hand side surface $(x=0.5)$, temperature is prescribed at $T=$ $300{ }^{\circ} \mathrm{C}$. The density is $\rho=3000 \mathrm{~kg} / \mathrm{m}^{3}$ and specific heat capacitance is $\mathrm{c}=125 \mathrm{~J} /\left(\mathrm{kg}{ }^{\circ} \mathrm{C}\right)$. Initially, temperature of the whole domain is at $T=0{ }^{\circ} \mathrm{C}$.

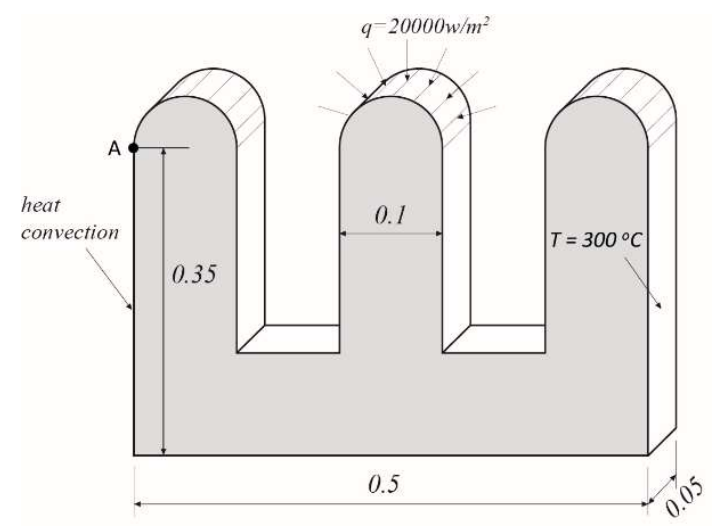

Figure 7. Example 4.3: Geometry and boundary condition

A mesh of 7430 four-node tetrahedral elements (1847 nodes) are used to discretize the problem domain. The snapshot matrix $\mathbf{T}_{\text {snap }}$ is taken by solution of the full problem from $t=0$ to $t=500 \mathrm{~s}$ with time increment $\Delta \mathrm{t}=5 \mathrm{~s}$ (i.e. 100 time steps). Singular decomposition of $\mathbf{T}_{\text {snap }}$ reveals that it is reasonable to select 22 POD bases for the reduced problem. The $22^{\text {th }}$ singular value is of magnitude $10^{-9}$. The reduced-problem is then solved from $\mathrm{t}=$ 0 to $\mathrm{t}=5000$ s using 1000 time steps. Variation of temperature at point A (see Figure 7) with respect to time is presented in Figure 8, showing that solution has reached steady-state after 5000s. Elapsed time for the CTH4-POD solution (including both the time needed to generate snapshot matrix and the time needed to solve the reduced problem) is approximately 272 seconds.

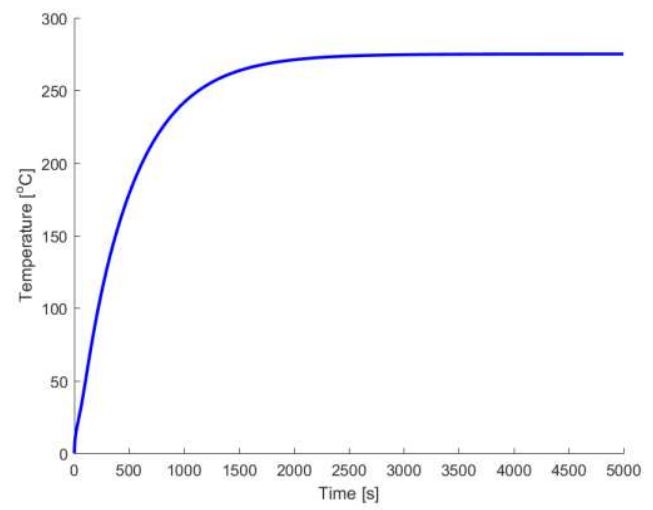

Figure 8. Example 4.3: Variation of temperature at point A (see Figure 7) with respect to time

Table 5. Example 4.3: Relative errors between CTH4 and CTH4-POD values at various periods

\begin{tabular}{|c|c|c|c|c|}
\hline Time & $50 \mathrm{~s}$ & $500 \mathrm{~s}$ & $1500 \mathrm{~s}$ & $3000 \mathrm{~s}$ \\
\hline $\begin{array}{c}\text { Relative } \\
\text { Errors }\end{array}$ & $0.07 \%$ & $0.03 \%$ & $0.02 \%$ & $0.02 \%$ \\
\hline
\end{tabular}

For comparison, the full-size problem for a time span from $t=0$ to $t=5000$ s is solved by 1000 time steps using the same mesh of 7430 CTH4 elements. Elapsed time is approximately 320 seconds. Relative errors between CTH4-POD solution with CTH4 solution at $t=50 \mathrm{~s}, t=500 \mathrm{~s}, t=1500 \mathrm{~s}$ and $t$ $=3000 \mathrm{~s}$ are reported in Table 5 . All the errors are least than $1 \%$, demonstrating the high accuracy of the POD approximation, although only 22 degrees of freedom are used in the reduced problem, instead of 1847 degrees of freedom in case of the full-size problem. Figure 9 depicts the $y$-component of heat flux obtained by CTH4-POD and TH4 elements (standard FEM). As expected, the CTH4POD results are smooth, while that of TH4 are nonphysically discontinuous across nodes. 


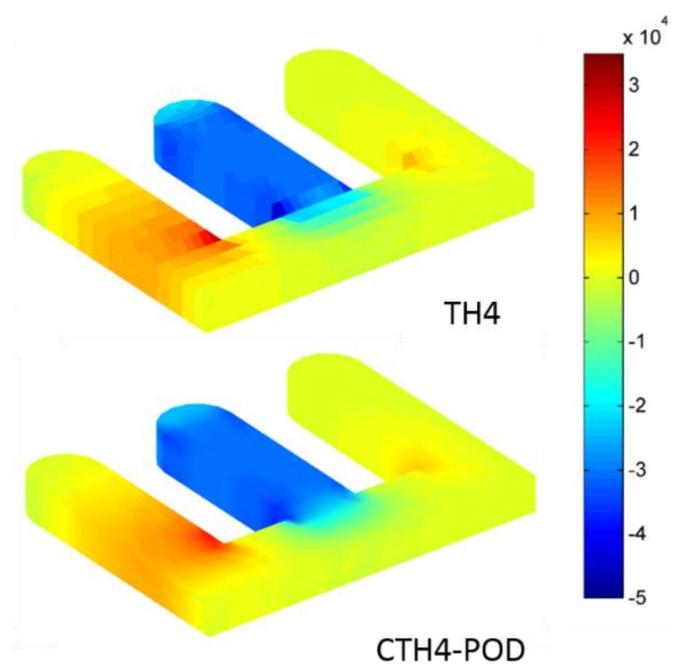

Figure 9. Example 4.3: the $y$-component of heat flux obtained by TH4 (upper) and CTH4-POD (lower)

\section{CONCLUSIONS.}

Two novel techniques have been investigated to improve finite element analysis of transient heat transfer problems. The consecutive-interpolation finite element method (CFEM) helps to "upgrade" a wide range of standard finite elements types such that the approximation accuracy is higher and the gradient field is smooth. In term of computational efficiency, Proper Orthogonal Decomposition (POD) effectively shortens elapsed time while advantages of CFEM are still maintained. Although in the numerical examples, only CQ4 and CTH4 elements are considered as representatives for two-dimensional elements and three-dimensional elements, respectively, the CFEM-POD procedure for other types of element is expected to be the same.

\section{REFERENCES}

[1] O. C. Zienkiewicz and R. L. Taylor, The Finite Element Method - Volume 1: The Basis, fifth edition ed., Butterworth - Heinemann, 2000.

[2] G. R. Liu, Meshfree Methods: Moving Beyond the Finite Element Method, Second ed., Taylor and Francis, 2010.

[3] L. C. Wrobel and C. A. Brebbia, Boundary Element Methods in Heat Transfer, Springer, 1992.

[4] I. V. Singh, "A numerical solution of composite heat transfer problems using meshless method," International Journal of Heat and Mass Transfer, vol. 47, no. 10-11, pp. 2123-2138, 2004.

[5] X. Y. Cui, S. Z. Feng and L. G. Y., "A cell-based smoothed radial point interpolation method (CS-RPIM) for heat transfer analysis," Engineering Analysis with Boundary Elements, vol. 40, pp. 147-153, 2014.

[6] C. Zheng, S. C. Wu, X. H. Tang and J. H. Zhang, "A novel twice-interpolation finite element method for solid mechanics problems," Acta Mechanica Sinica, vol. 26, pp. 265-278, 2010.

[7] Q. T. Bui, Q. D. Vo, C. Zhang and D. D. Nguyen, "A consecutive-interpolation quadrilateral element (CQ4): Formulation and Applications," Finite Element in Analysis and Design, vol. 84, pp. 14-31, 2014.

[8] N. M. Nguyen, T. N. Nguyen, Q. T. Bui and T. T. Truong, "A consecutive-interpolation finite element method for heat transfer analysis," Science \& Technology Development Journal, vol. 18, no. K4, pp. 21-28, 2015.

[9] N. M. Nguyen, Q. T. Bui, T. T. Truong, A. N. Trinh, I. V. Singh, T. Yu and H. D. Doan, "Enhanced nodal gradient 3D consecutive-interpolation tetrahedral element (CTH4) for heat transfer analysis," International Journal of Heat and Mass Transfer, vol. 103, pp. 14-27, 2016.

[10] S. Han and B. Feeny, "Application of proper orthogonal decomposition to structural vibration analysis," Mechanical Systems and Signal Processing, vol. 17, no. 5, pp. 989-1001, 2003.

[11] R. A. Bialecki, A. J. Kassab and A. Fic, "Proper orthogonal decomposition and modal analysis for acceleration of transient FEM thermal analysis," International Journal of Numerical Methods in Engineering, vol. 62, pp. 774-797, 2005.

[12] X. Zhang and H. Xiang, "A fast meshless method based on proper orthogonal decomposition for the transient heat conduction problems," International Journal of Heat and Mass Transfer, vol. 84, pp. 729-739, 2015.

[13] B. Dai, B. Zheng and L. Wang, "Numerical solution of transient heat conduction problems using improved meshless local Petrov-Galerkin method," Applied Mathematics and Computation, vol. 219, no. 19, pp. 10044-10052, 213.

Nguyen Ngoc Minh received the B.E. degree (2008) in Engineering Mechanics from Ho Chi Minh city University of Technology, VNU-HCM Viet Nam, and M.E. degree (2011) in Computational Engineering from Ruhr University Bochum, Germany.

$\mathrm{He}$ is a Lecturer, Department of Engineering Mechanics, Ho Chi Minh City University of Technology, VNU-HCM. His current interests include heat transfer analysis, fracture analysis and numerical methods.

Nguyen Thanh Nha received the B.E. (2007) and M.E. (2011) degrees in Engineering Mechanics from Ho Chi Minh city University of Technology, VNU-HCM. 
He is a Lecturer, Department of Engineering Mechanics, Ho Chi Minh City University of Technology, VNU-HCM. His current interests include fracture analysis in composite materials and numerical methods.

Bui Quoc Tinh received his Bachelor degree (2002) in Mathematics from University of Science, VNU-HCM, Ho Chi Minh city, Viet Nam; M. E degree (2006) from University of Liege, Belgium and PhD degree (2009) from Technical University of Vienna, Austria.

$\mathrm{He}$ is an Associate Professor, Department of Civil and Environmental Engineering, Tokyo Institute of Technology, Japan. His current interests include fracture analysis, damage analysis and numerical methods.

Truong Tich Thien received his B.E. (1986) and M.E. (1992) and PhD degrees in Mechanical
Engineering from Ho Chi Minh city University of Technology, VNU-HCM.

$\mathrm{He}$ is an Associate Professor, Department of Engineering Mechanics, Ho Chi Minh City University of Technology, VNU-HCM. His current interests include fracture analysis and numerical methods. 


\title{
Phân tích truyền nhiệt quá độ bằng kỹ thuật nội suy liên tiếp và phân rã trực giao
}

\author{
Nguyễn Ngọc Minh ${ }^{1}$, Nguyễn Thanh Nhã ${ }^{1}$, Trương Tích Thiện ${ }^{1, *}$, Bùi Quốc Tính ${ }^{2}$ \\ ${ }^{1}$ Trường Đại học Bách Khoa, ĐHQG-HCM \\ ${ }^{2}$ Viện Công nghệ Nhật Bản \\ Tác giả liên hệ: tttruong@hcmut.edu.vn
}

Ngày nhận bản thảo: 07-3-2017, ngày chấp nhận đăng: 20-11-2017

Tóm tắt-Kỹ thuật nội suy liên tiếp đã được biết đến như một giải pháp cải tiến phương pháp phần tử hữu hạn truyền thống nhằm mang lại lời giải số có độ chính xác cao hơn. Thêm nữa, trường đạo hàm thu bởi phương pháp này, còn gọi là phương pháp Phần tử hữu hạn Nội suy liên tiếp (CFEM) là một trường trơn, thay vì bất liên tục khi qua biên phần tử như trong FEM. Với bài báo này, kỹ thuật nội suy liên tiếp được ứng dụng để phân tích bài toán truyền nhiệt quá độ. Nhằm cải thiện hiệu năng tính toán, kỹ thuật thu gọn mô hình bằng phân rã trực giao (POD) được giới thiệu. Ý tưởng của giải pháp này là ánh xạ bài toán lớn về bài toán nhỏ hơn, nhờ đó đẩy nhanh quá trình giải, trong khi vẫn đảm bảo độ chính xác mong muốn. Bằng các phép biến đổi toán học, một nhóm hàm cơ sở POD phục vụ cho phép ánh xạ sẽ được xác định. Thông qua việc kết họ̣p CFEM và POD, ưu điểm của CFEM được kì vọng sẽ duy trì, đồng thời tiết kiệm thời gian tính toán.

Tù̀ khóa-truyền nhiệt quá độ ba chiều, CFEM, POD, nội suy liên tiếp. 